\title{
EFEITOS DO BIOSSÓLIDO DE SUINOCULTURA EM LATOSSOLO E NA PRODUÇÃO DE FEIJÃO
}

\author{
Rafael Henrique Gonçalves ${ }^{1}$; Carlos Antonio Centuriòn Maciel ${ }^{2}$
}

\begin{abstract}
RESUMO
Este experimento realizado em casa de vegetação, no campus da UNIPINHAL, teve como objetivo avaliar os efeitos da aplicação do biossólido nas propriedades físicas e químicas de um Latossolo Vermelho-Amarelo distrófico e na produção de grãos da cultura do feijão (Phaseolus vulgaris L.). Para tanto, prepararam-se 8 tratamentos em triplicata em vasos, contendo $8 \mathrm{~kg}$ do referido solo. Foram agregadas dosagens crescentes de biossólido, gerado numa suinocultura do Campus experimental, correspondentes a $0,10,20,30,40,50,60,70 \mathrm{Mg}_{\text {ha }}{ }^{-1}$. Posteriormente, coletaram-se amostras do solo de cada tratamento para determinação de $\mathrm{pH}$ e teores de matéria orgânica, $\mathrm{P}, \mathrm{K}, \mathrm{S}, \mathrm{Ca}, \mathrm{Mg}, \mathrm{Al}$, $\mathrm{H}+\mathrm{Al}$, C.T.C., V\%. Também foram determinados os seguintes micronutrientes: B, Fe, Mn, Cu e Zn. Três plantas de feijão cultivar IAC - carioca foram cultivadas em vaso. Após 97 dias, coletaram-se e pesaram-se as sementes produzidas. A aplicação do biossólido elevou de forma linear o $\mathrm{pH}$, os teores de M.O., de micronutrientes e macronutrientes, com exceção do fósforo e da saturação por bases, que tiveram elevação com comportamento quadrático. A aplicação da dosagem de $60 \mathrm{Mg} \cdot \mathrm{ha}^{-1}$ promoveu a maior produção, sendo de $81,08 \mathrm{~g}$ para 9 plantas. Para dosagens superiores, ocorreu efeito inibidor na produção devido ao provável excesso de alguns nutrientes.
\end{abstract}

Palavras-chave: Phaseolus vulgaris, suíno, nutrientes.

\section{ABSTRACT \\ Effect of Swine Farm Biosolids in Latossolo and on Bean Production}

The experiment, conducted in a greenhouse on UNIPINHAL Campus, aimed to evaluate the effects of swine farm biosolids on physical and chemical properties of Latossolo "Vermelho-Amarelo" (RedYellow) dystrophic soil and on yield of dry beans (Phaseolus vulgaris L.). Initially, eight treatments were prepared in triplicate in pots containing 8 kilograms soil mixed with swine farm biosolids corresponding to $0,10,20,30,40,50,60,70 \mathrm{Mg} \mathrm{ha}^{-1}$. The biosolids were obtained from the swine farm of the experimental Campus. Before planting, samples were collected from each treatment to determine $\mathrm{pH}$, organic matter content, $\mathrm{P}, \mathrm{K}, \mathrm{S}, \mathrm{Ca}, \mathrm{Mg}, \mathrm{Al}, \mathrm{H}+\mathrm{Al}, \mathrm{C} . \mathrm{E} . \mathrm{C} ., \mathrm{V} \%$. The micronutrients $\mathrm{B}$, $\mathrm{Fe}, \mathrm{Mn}, \mathrm{Cu}$ and $\mathrm{Zn}$ were also determined. Each pot was plantes three bean plants, and the seeds yield was determined after 97 days. The swine biosolid application raised the $\mathrm{pH}$, the organic matter content, micronutrients and macronutrients steadily, and increase of phosphorus and saturated bases was quadratic. The maximum yield of $81,08 \mathrm{~g}$ per pot was obtained from plants growing in soil mixed with $60 \mathrm{Mg} \cdot \mathrm{ha}^{-1}$ of the biosolids. The yield was reduced at higher application rates probably due to excess of elements in the soil.

Keywords: Phaseolus vulgaris, swine, nutrients.

\footnotetext{
Recebido para publicação em 08.05.2007

${ }^{1}$ Engenheiro Ambiental, aluno do Programa de Pós-Graduação em Geociências e Meio Ambiente, IGCE, UNESP, Rio Claro, SP. E-mail: lothar82@uol.com.br

${ }^{2}$ Prof. Doutor do Centro Regional Universitário de Espírito Santo do Pinhal (UNIPINHAL), Espírito Santo do Pinhal, SP. Email: centurion@unipinhal.edu.br
} 


\section{INTRODUÇÃO}

No Brasil a suinocultura é uma atividade predominante em pequenas propriedades rurais e importante do ponto de vista social, econômico e, especialmente, como instrumento de fixação do homem no campo. Cerca de $81,7 \%$ dos suínos são criados em unidades de até 100 hectares. Esta atividade é encontrada em $46,5 \%$ das 5,8 milhões de propriedades existentes no país, empregando mão de obra tipicamente familiar e constituindo uma importante fonte de renda e de estabilidade social (PERDOMO et al., 2001).

A maioria dessas propriedades não possui instalações adequadas para o armazenamento e tratamento dos dejetos, os quais são lançados seu lançamento em cursos d'água, promovendo a poluição de águas superficiais e subterrâneas. Portanto, é desejável que todo suinocultor tenha um programa racional de controle dos dejetos.

Existem vários processos que podem ser utilizados para o tratamento de dejetos de suínos, sendo os processos biológicos os mais empregados (KUNZ, 2005).

Os sistemas de tratamento anaeróbio, movidos por processos biológicos, têm se mostrado uma forma eficiente de saneamento. Nesse sistema, o uso do reator anaeróbio compartimentado, seguido de leitos cultivados com macrófitas, cria uma expectativa e uma alternativa a mais para se tratar este resíduo (TOBIAS, 2002).

No decorrer do tempo, entretanto, uma parcela insolúvel conhecida como lodo, correspondente em média a $0,1 \%$ do volume total do efluente da instalação, deposita-se no fundo dos compartimentos, sendo necessária sua remoção. Após sua secagem e bioestabilização, ela recebe a denominação de biossólido.

Um possível destino do biossólido é como fonte de energia e nutriente para outras espécies animais. Entretanto, do ponto de vista sanitário e ambiental, sua utilização como fertilizante é considerada mais adequada.

Os dejetos de suínos têm sido utilizados como fertilizante do solo, pois possuem elementos químicos, que podem se constituir em nutrientes para o desenvolvimento das plantas, da mesma forma como aqueles empregados nos fertilizantes químicos, além de melhorarem as condições físicas e biológicas do solo (SEGANFREDO, 2000).

Com base nestas informações, o objetivo deste trabalho foi avaliar os efeitos da aplicação de biossólido nas propriedades físicas e químicas de um Latossolo Vermelho-Amarelo distrófico, bem como na produção de grãos da cultura do feijão (Phaseolus vulgaris L.).

\section{MATERIAL E MÉTODOS}

No presente trabalho as atividades de caráter experimental foram realizadas em casa de vegetação provida de cobertura plástica e proteção lateral de sombrite preto $50 \%$, nas dependências do Centro Regional Universitário de Espírito Santo do Pinhal (UNIPINHAL) em Espírito Santo do Pinhal, enquanto as de caráter analítico foram realizadas no Laboratório de Solos localizado no UNIPINHAL, durante o período de outubro de 2004 a março de 2005.

A etapa experimental constituiu-se do preparo de oito tratamentos com três repetições em delineamento experimental inteiramente casualizado, utilizando-se vasos de plástico contendo $8 \mathrm{Kg}$ de solo peneirado (malha $2 \mathrm{~mm}$ ), obtido à profundidade $0-0,2$ $\mathrm{m}$ na área de experimentação agrícola do UNIPINHAL. Ao solo dos vasos, foram adicionadas dosagens crescentes do biossólido de suínos correspondentes a 0 , $10,20,30,40,50,60,70 \mathrm{Mg}$. ha ${ }^{-1}$, as quais foram homogeneizadas e colocadas à capacidade de campo vindo a permanecer incubadas durante 40 dias a fim de possibilitar a absorção dos elementos químicos existentes no biossólido pelo solo.

Após esse período, em 22 de outubro de 2004 , os vasos foram semeados com 5 sementes de feijão cultivar IAC - carioca e irrigados, diariamente. Em seguida, com a germinação, aos 12 dias, em 02 de novembro de 2004, realizou-se o desbaste de algumas plantas, deixando três plantas por vaso. Aos 97 dias, em 26 de janeiro de 2005, coletaram-se e pesaram-se as sementes produzidas. 
$\mathrm{Na}$ etapa analítica, a primeira tarefa foi a realização de uma classificação textural do solo utilizado como base, por meio do método do densímetro proposto por Lemos \& Santos (1984), vindo a corresponder a um Latossolo Vermelho-Amarelo distrófico, segundo a classificação proposta pela Embrapa (1999). As frações de areia, argila e silte encontradas foram de 330, 560 e 110 g. kg respectivamente, sendo, assim, classificado como de textura argilosa. Ainda, neste solobase, as características químicas foram analisadas de acordo com Raij \& Quaggio (1983), sendo descritas nos quadros 1 e 2 .

Utilizando balão volumétrico de $50 \mathrm{~cm}^{3}$, determinaram-se a densidade aparente $\left(1,25 \mathrm{~g} \cdot \mathrm{cm}^{-3}\right)$, a densidade real $\left(2,20 \mathrm{~g} \cdot \mathrm{cm}^{-3}\right) \mathrm{e}$, embasado nesses dados primários, verificouse um volume de poros totais de $43,2 \%$ para este solo-testemunha. Utilizando-se o mesmo método determinaram-se densidade aparente, densidade real e volume de poros totais para os solos dos tratamentos.

A etapa analítica consistiu também de amostragem do solo de cada tratamento para determinação de $\mathrm{pH}$ e teores de M.O., P, K, S, Ca, Mg, Al, H + Al, C.T.C. e V\%. Também foram determinados os seguintes micronutrientes: $\mathrm{B}, \mathrm{Fe}, \mathrm{Mn}, \mathrm{Cu}$ e $\mathrm{Zn}$.

Utilizou-se um biossólido proveniente da estação de tratamento de efluente de suinocultura localizada no Campus I e constituída por um reator anaeróbio compartimentado. O lodo foi retirado das câmaras e, em seguida, colocado sobre lona plástica preta e seco ao sol. Os teores totais de nutrientes foram avaliados de acordo com Malavolta et al. (1989), sendo apresentados nos quadros 3 e 4 .

Quadro 1. Teores de matéria orgânica (M.O.), pH e macronutrientes do Latossolo Vermelho-Amarelo distrófico em Espírito Santo do Pinhal, no ano 2005

\begin{tabular}{|c|c|c|c|c|c|c|c|c|c|c|c|c|}
\hline & M.O. & $\mathrm{pH}$ & $\mathbf{P}$ & $s$ & $\mathrm{~K}$ & $\mathrm{Ca}$ & $\mathbf{M g}$ & Al & SB & $\mathrm{H}+\mathrm{Al}$ & СтC & $\mathbf{v}$ \\
\hline & $\mathrm{g} \mathrm{dm}^{-3}$ & $\mathrm{CaCl}$ & _mg & $\mathrm{m}^{-3}$ & & & & $\overline{\mathrm{mo}}$ & & & & (\%) \\
\hline Solo-padrão & 11 & 4,7 & 6 & 6 & 1 & 5 & 2 & 1 & 8 & 25 & 33 & 24 \\
\hline
\end{tabular}

SB: Soma das bases $(\mathrm{Ca}+\mathrm{Mg}+\mathrm{K})$

H + Al: Acidez potencial

CTC: Capacidade de troca catiônica

V: Saturação por bases

Quadro 2. Teores de micronutrientes do Latossolo Vermelho-Amarelo distrófico, em Espírito Santo do Pinhal, no ano 2005

\begin{tabular}{|c|c|c|c|c|c|}
\hline & B & $\mathrm{Cu}$ & $\mathrm{Fe}$ & Mn & Zn \\
\hline & \multicolumn{5}{|c|}{$\mathrm{mg} \mathrm{dm}^{-3}$} \\
\hline Solo-padrão & 0,42 & 1,2 & 42 & 4,6 & 6,2 \\
\hline
\end{tabular}

Quadro 3. Teores totais de matéria orgânica (M.O.), $\mathrm{pH}$ e macronutrientes do biossólido proveniente da estação de tratamento de efluente de suinocultura, em Espírito Santo do Pinhal, no ano de 2005

\begin{tabular}{|c|c|c|c|c|c|c|c|c|c|c|c|c|}
\hline & M.O. & $\mathrm{pH}$ & $\mathbf{P}$ & $S$ & $\mathrm{~K}$ & $\mathrm{Ca}$ & Mg & Al & SB & $\mathrm{H}+\mathrm{Al}$ & стC & V \\
\hline & $\mathrm{g} \mathrm{dm}^{-3}$ & $\mathrm{CaCl}$ & & 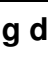 & & & & & $\mathrm{l}_{\mathrm{c}} \mathrm{dm}$ & & & (\%) \\
\hline Biossólido & 235 & 6,6 & 230 & 23 & 21,8 & 174 & 46 & 1 & 241,8 & 25 & 266,8 & 91 \\
\hline
\end{tabular}

Quadro 4. Teores totais de micronutrientes do biossólido proveniente da estação de tratamento de efluente de suinocultura, em Espírito Santo do Pinhal, no ano de 2005

\begin{tabular}{|c|c|c|c|c|c|}
\hline & B & $\mathrm{Cu}$ & $\mathrm{Fe}$ & Mn & $\mathrm{Zn}$ \\
\hline & \multicolumn{5}{|c|}{$\mathrm{mg} \mathrm{dm}^{-3}$} \\
\hline Biossólido & 0,64 & 52,6 & 49 & 24,8 & 14,6 \\
\hline
\end{tabular}


Para a análise estatística dos resultados, os dados obtidos foram submetidos à análise do coeficiente de correlação, sendo as médias comparadas pelo teste de Tukey (ZAR, 1984), utilizando-se o nível 5\% de significância.

\section{RESULTADOS E DISCUSSÃO}

Os resultados relativos à etapa analítica do estudo são ilustrados nas figuras 1, 2, 3, 4, 5, 6 e 7. Na Figura 1, observa-se que o aumento da dosagem do biossólido produziu uma redução linear da densidade aparente do solo, sendo inicialmente de $1,25 \mathrm{~g} . \mathrm{cm}^{-3}$ para o solopadrão a até $1,19 \mathrm{~g} \cdot \mathrm{cm}^{-3}$ para último 0 tratamento com a dose $70 \mathrm{Mg}^{-h^{-1}}{ }^{-1}$, efeito este esperado, quando se adiciona um composto orgânico ao solo.

O volume de poros totais obteve um acréscimo, comportamento este inversamente proporcional ao da densidade aparente, em conseqüência do surgimento de maior número de espaços "vazios" no substrato, provocado pela adição do composto (Figura 1). Kiehl (1979) atribui este acréscimo na porosidade, principalmente, ao aumento da disponibilidade do carbono em solo, o qual é abundante em compostos orgânicos como o biossólido. Ressalta, ainda, que o volume de poros totais é significativo para $o$ crescimento $e$ desenvolvimento de plantas.

Os teores disponíveis de matéria orgânica nos tratamentos obtiveram um aumento linear, em razão da aplicação do composto orgânico (Figura 2), sendo um aumento médio de $0,9 \mathrm{~g} \cdot \mathrm{dm}^{-3}$ para cada 10 Mg.ha ${ }^{-1}$ de resíduo aplicado.

Constataram-se acréscimos nos valores de $\mathrm{pH}$, durante as adições de biossólido, devido à alcalinidade do composto (Figura 2). Nota-se que o tratamento de dose 70 Mg.ha ${ }^{-1}$ obteve o mesmo $\mathrm{pH}$ do biossólido. Fageria et al. (2004) constataram que o melhor pH, para obtenção de alta produtividade no feijoeiro, situa-se entre 6,5 e 7,0 .
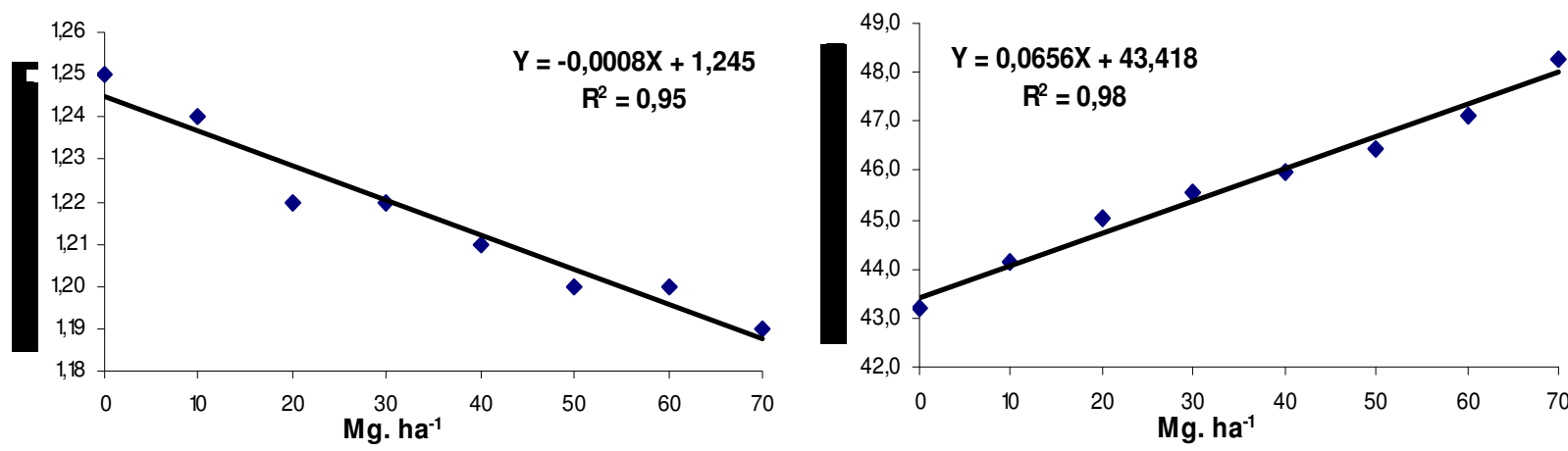

Figura 1. Densidade aparente do solo e volume de poros totais em função das aplicações das doses de biossólido, em Espírito Santo do Pinhal, no ano 2005.
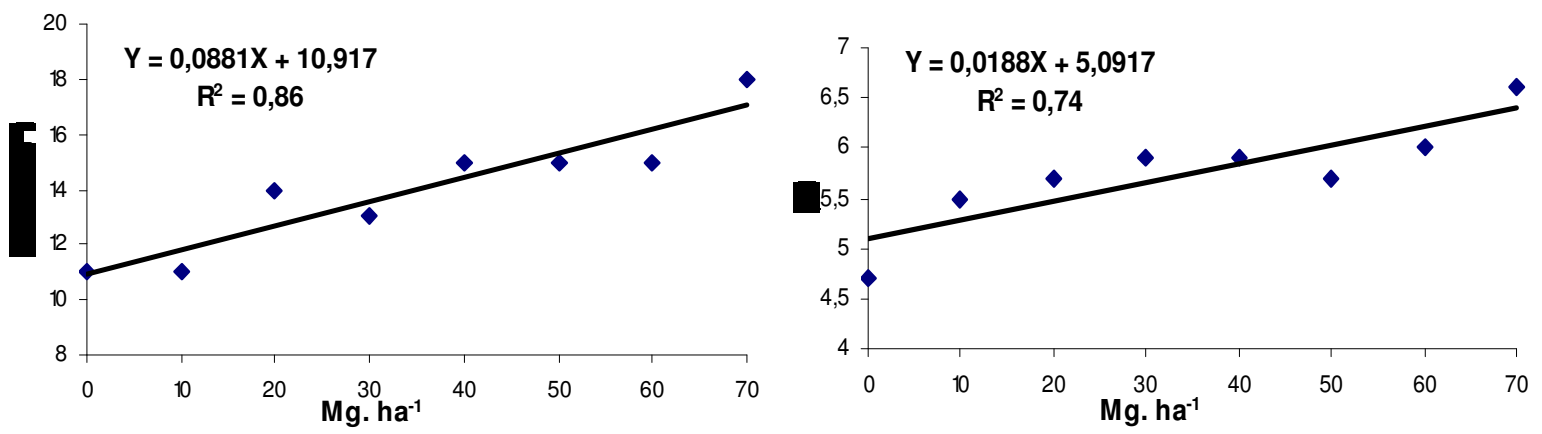

Figura 2. Matéria orgânica (M.O.) e pH do solo em função das aplicações das doses de biossólido, em Espírito Santo do Pinhal, no ano 2005. 
Segundo os limites de interpretação de teores de fósforo $(\mathrm{P})$ disponível no solo, estabelecidos para culturas anuais no Estado de São Paulo (RAIJ et al., 1996), o teor de $\mathrm{P}$ teve um comportamento quadrático nos tratamentos, passando da classe baixo $\left(6,0 \mathrm{mg} \cdot \mathrm{dm}^{-3}\right)$ para muito alto a partir da primeira dose de $10 \mathrm{Mg}^{-h^{-1}} \mathrm{de}^{-1}$ biossólido (Figura 3). Nota-se que mesmo nas dosagens iniciais, os teores de $P$ atingiram elevados valores. Fageria et al. (2004) verificaram que o elemento $P$, seguido por nitrogênio $(\mathrm{N})$ e potássio $(\mathrm{K})$, é - que mais limita a produtividade na cultura do feijoeiro. Esses autores relataram ainda que, após ensaio com incremento de $P$ em feijoeiro os teores deste apresentaram comportamento quadrático, resultando uma produção máxima de matéria seca da parte aérea e dos grãos, quando foram aplicados 216 e $165 \mathrm{mg} . \mathrm{Kg}^{-1}$, respectivamente. Tobias (2002) também observou comportamento quadrático na disponibilidade de $\mathrm{P}$, após o tratamento deste tipo de Latossolo com doses crescentes de lodo de suinocultura.

Em relação ao potássio, houve uma variação linear no teor deste elemento químico no solo, em função da aplicação das doses de biossólido, obtendo-se um coeficiente de determinação positivo substancial $\left(R^{2}=0,78\right)$ (Figura 3$)$. Da mesma forma que Tobias (2002), verificouse que o aumento deste nutriente não foi suficiente para mudar a classe de sua disponibilidade, permanecendo classificado como baixo (RAlJ et al., 1996). Este comportamento é esperado, uma vez que - elemento potássio encontra-se predominantemente sob forma iônica nas águas residuárias, enquanto, durante os processos de biodigestão, permanece em solução, além de possuir alta taxa de lixiviação, o que explica as baixas concentrações do elemento em lodos (TSUTIYA, 2001).

As quantidades de enxofre (S) disponíveis apresentaram um leve avanço linear, porém o acréscimo nos teores com o aumento nas dosagens de biossólido não foram suficientes para ultrapassar a classe média de disponibilidade do nutriente (RAlJ et al., 1996) (Figura 4). O comportamento dos teores de $\mathrm{S}$, durante as dosagens do resíduo seguiu a mesma tendência da matéria orgânica, efeito este que está, provavelmente, relacionado ao processo de mineralização da m.o., observado também por Silva et al. (2001).

As doses de biossólido proporcionaram aumento nos teores de cálcio (Ca) disponível com tendência linear, transpondo os teores da classe médio $(5,0$ $\mathrm{mmol}_{\mathrm{c}} \cdot \mathrm{dm}^{-3}$ ) do tratamento testemunha para classe alto, nos tratamentos que receberam doses do biossólido (Figura 4) (RAIJ et al., 1996). Tobias (2002) observou o mesmo comportamento para o nutriente $\mathrm{Ca}$, durante a aplicação de doses crescentes de lodo de suinocultura.
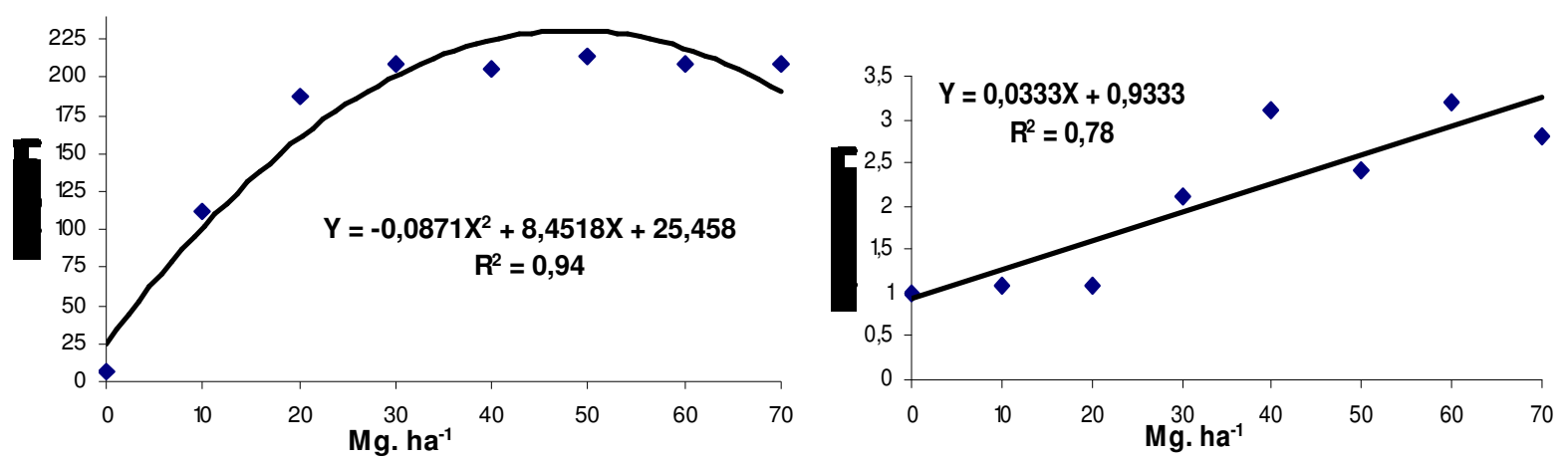

Figura 3. Teores de fósforo $(P)$ e potássio $(K)$ no solo em função das aplicações das doses de biossólido, em Espírito Santo do Pinhal, no ano de 2005. 

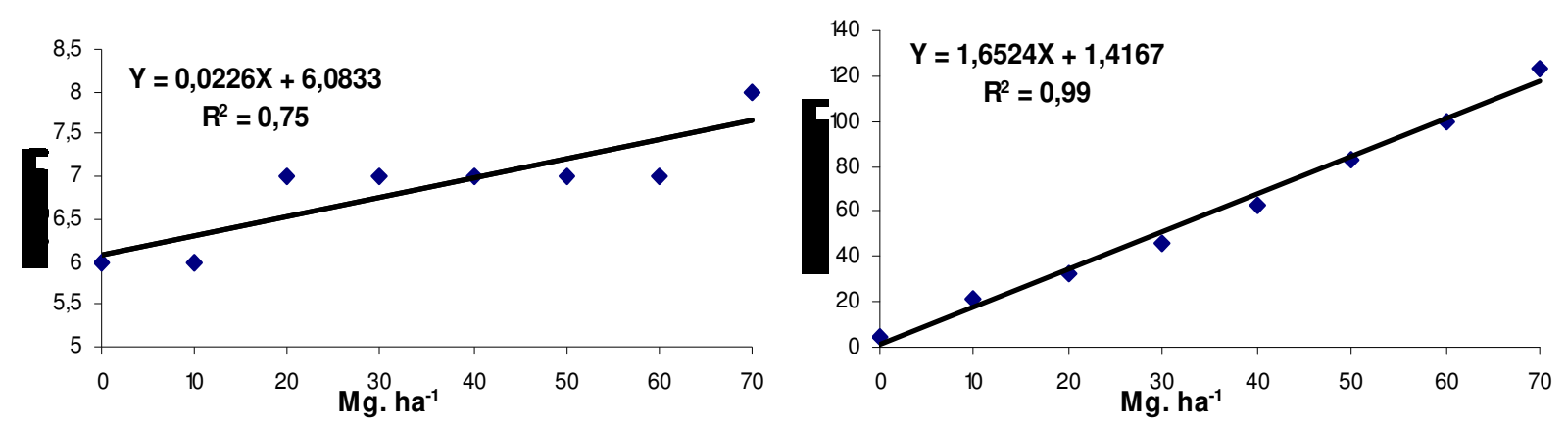

Figura 4. Teores de enxofre (S) e cálcio (Ca) no solo em função das aplicações das doses de biossólido, em Espírito Santo do Pinhal, no ano 2005.

As quantidades de magnésio (Mg) acumuladas, durante a aplicação do resíduo, aumentaram significativamente, obtendo um comportamento linear, efeito este igualmente observado por Tobias (2002). Os teores disponíveis do nutriente passaram da classe baixo $\left(2,0 \quad \mathrm{mmol}_{\mathrm{c}} \cdot \mathrm{dm}^{-3}\right)$ do tratamento testemunha para a classe alto nos tratamentos consecutivos (Figura 5) (RAlJ et al., 1996).

Em virtude dos aumentos nos teores trocáveis de $\mathrm{Ca}, \mathrm{Mg}$ e $\mathrm{K}$, com a aplicação do biossólido de suinocultura no solo, verificouse aumento proporcional na soma das bases no solo (Figura 5), ou seja, a cada dose de biossólido aplicado, houve aumento de 0,31, 4,57, 18,71 e $21,69 \mathrm{mmol}_{\mathrm{c}} \cdot \mathrm{dm}^{-3}$ de $\mathrm{K}, \mathrm{Mg}$, $\mathrm{Ca}$ e soma das bases, respectivamente. De acordo com a interpretação de Raij et al. (1996), os valores de soma de bases para os tratamentos avaliados foram da classe baixa $\left(8,0 \mathrm{mmol}_{\mathrm{c}} \cdot \mathrm{dm}^{-3}\right)$ no tratamento com solo padrão para classe média com a aplicação de $10 \mathrm{Mg}$. ha ${ }^{-1}$ de biossólido e, então, para classe alta para os demais tratamentos consecutivos.

Semelhante ao observado por Tobias (2002), verificou-se aumento nos valores da soma das bases e da acidez potencial $\left(\mathrm{H}^{+}+\right.$ $\mathrm{Al}^{3+}$ ), o que refletiu em crescimento linear do coeficiente de troca catiônica, diante da aplicação do resíduo no solo (Figura 6). Segundo a interpretação dos teores disponíveis em solo de Raij et al. (1996), enquanto a acidez potencial permaneceu na classe baixa apresentando valores menores que $28 \mathrm{mmol}_{\mathrm{c}} \cdot \mathrm{dm}^{-3}$ para todos os tratamentos, o coeficiente de troca catiônica passou da classe baixa do solo padrão para a classe média durante a adição das dosagens de 10, 20 e $30 \mathrm{Mg} \mathrm{ha}^{-1}$ de resíduo e para a classe alta nos tratamentos restantes com maiores dosagens.
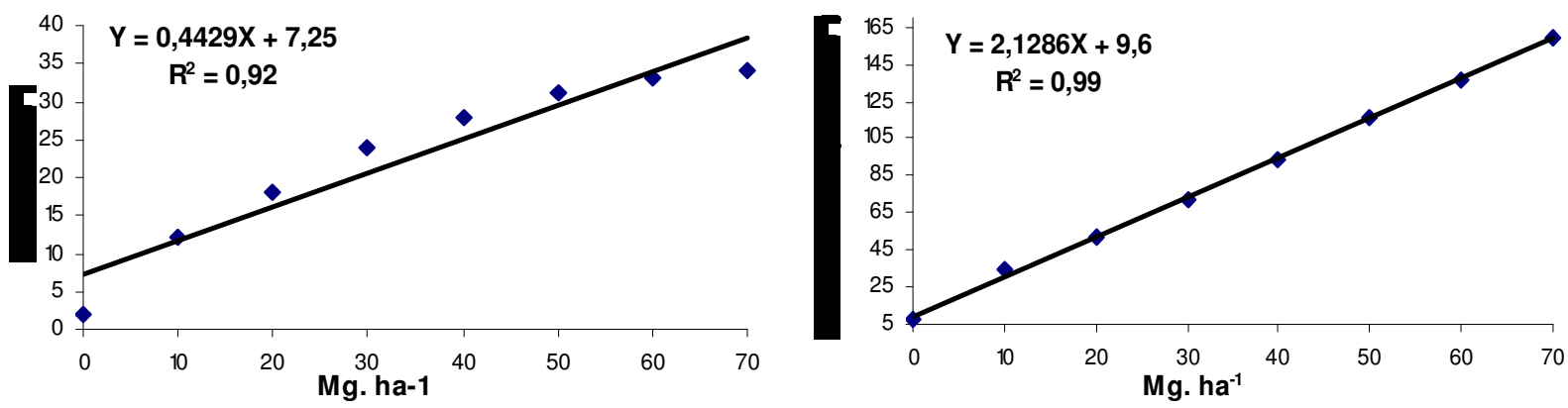

Figura 5. Teores de magnésio $(\mathrm{Mg})$ e valores para soma das bases ( $\mathrm{Ca}, \mathrm{Mg}$ e $\mathrm{K}$ ) no solo em função das aplicações das doses de biossólido, em Espírito Santo do Pinhal, no ano 2005. 

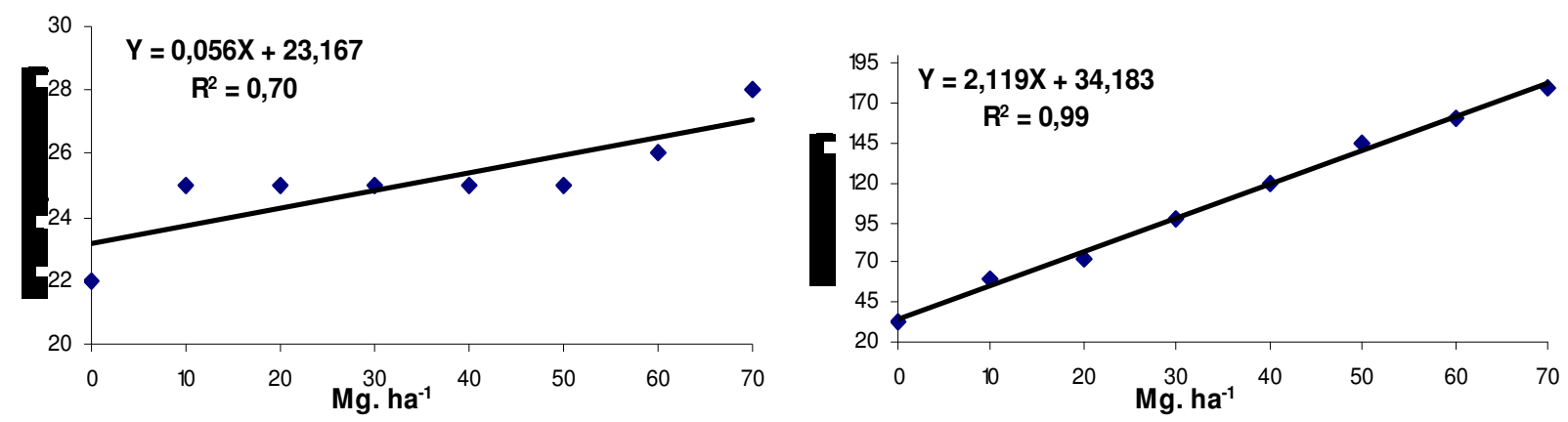

Figura 6. Capacidade de troca catiônica (CTC) e acidez potencial $\left(\mathrm{H}^{+}+\mathrm{Al}^{3+}\right)$ no solo em função das aplicações das doses de biossólido, em Espírito Santo do Pinhal, no ano 2005.

Os valores para saturação por bases (V\%) apresentaram comportamento quadrático (Figura 7). Tal comportamento também foi constatado em experimentos, conduzidos por Tobias (2002). Fageria et al. (2004) verificaram que a saturação por bases adequadas, para uma produção máxima de grãos da leguminosa em questão está em torno de $70 \%$. Conforme a interpretação dos percentuais para a saturação por bases, proposta por Raij et al. (1996), os valores passaram da classe muito baixa no tratamento testemunha para

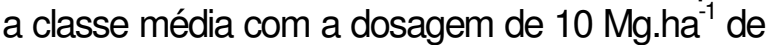
biossólido, permanecendo os demais tratamentos consecutivos na classe alto e acima de $70 \%$ de saturação.

Quanto à produção de grãos, a aplicação do biossólido elevou a produtividade em relação ao tratamento testemunha (Tabela 5). No tratamento correspondente à aplicação de $70 \mathrm{Mg} \cdot \mathrm{ha}^{-1}$ de biossólido, a produção apresentou queda. Comportamentos similares, que apresentavam declínio de produção em aplicações acima de 60 Mg.ha' ${ }^{-1}$ de biossólido em Latossolo VermelhoAmarelo distrófico, foram observados por Tobias (2002) na produção de grãos do feijoeiro, assim como na matéria seca de alface por Tobias et al. (2001).

Dentre os macronutrientes avaliados, de acordo com Malavolta (1982), as exigências nutricionais da cultura do feijoeiro no solo foram obtidas para $\mathrm{P}, \mathrm{K}, \mathrm{Ca}$ e $\mathrm{Mg}$ em todos os tratamentos, com exceção do $S$, que não alcançou o teor nutricional mínimo exigido em nenhum dos tratamentos.

Os valores de alumínio trocável (Al) mantiveram-se constantes em todos os tratamentos na taxa de $1 \mathrm{mmol}_{\mathrm{c} .} \mathrm{dm}^{-3}$, designando a ausência deste elemento no resíduo.

Em vista da aplicação do biossólido, o acúmulo foi progressivo para os micronutrientes cobre (Cu), zinco $(\mathrm{Zn})$, ferro $(\mathrm{Fe})$, boro $(\mathrm{B})$ e manganês $(\mathrm{Mn})$. Para $\mathrm{Cu}, \mathrm{Zn}$ e $\mathrm{Fe}$, os teores se enquadraram na classe alta para todos os tratamentos, assim como o $\mathrm{B}$, na classe média. Para o micronutriente $\mathrm{Mn}$, nos tratamentos em que se adicionou biossólido, ocorreu acúmulo de teores, o que promoveu a passagem da classe média (solo padrão) para a classe alta de disponibilidade do nutriente (RAIJ et al., 1996).

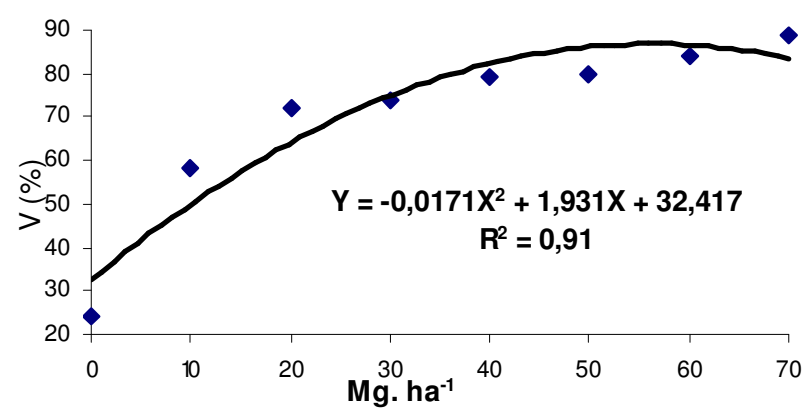

Figura 7. Porcentagem de saturação por bases (V\%) no solo em função das aplicações de doses de biossólido, em Espírito Santo do Pinhal, no ano 2005. 
Quadro 5. Produção média e produtividade de grãos de feijão em função da aplicação do biossólido, em Espírito Santo do Pinhal, no ano 2005

\begin{tabular}{|c|c|c|c|}
\hline $\begin{array}{l}\text { Dose biossólido (equivalente) } \\
\text { (ton.ha }{ }^{-1} / \mathrm{Mg} \mathrm{ha}^{-1} \text { ) }\end{array}$ & $\begin{array}{l}\text { Produtividade } \\
\text { (g/vaso) }\end{array}$ & $\begin{array}{c}\text { Produção total } \\
\text { (g) }\end{array}$ & $\begin{array}{r}\text { Tukey } \\
(5 \%)\end{array}$ \\
\hline 0 & 11,34 & 34,01 & c \\
\hline 10 & 15,12 & 45,35 & $\mathrm{bc}$ \\
\hline 20 & 15,64 & 46,92 & $\mathrm{bc}$ \\
\hline 30 & 20,85 & 62,54 & $a b$ \\
\hline 40 & 23,47 & 70,14 & a \\
\hline 50 & 24,04 & 72,13 & a \\
\hline 60 & 27,03 & 81,08 & a \\
\hline 70 & 19,72 & 59,15 & $a b$ \\
\hline F: 11,42 & C.V.(\%): 13,78 & 7,80 & \\
\hline
\end{tabular}

Obs.: Medidas seguidas pelas mesmas letras são iguais estatisticamente a $5 \%$ de probabilidade.

F: Estatística do fator F.

C.V.(\%): Coeficiente de Variância entre as médias das produções totais de grãos.

D.M.S.: Diferença Mínima Significativa

\section{CONCLUSÕES}

- A aplicação do biossólido de suinocultura aumentou os teores de matéria orgânica, $\mathrm{P}, \mathrm{K}, \mathrm{S}, \mathrm{Ca}, \mathrm{Mg}$, alumínio trocável $(\mathrm{Al})$, acidez potencial $\left(\mathrm{H}^{+}+\mathrm{Al}^{3+}\right)$, bem como a capacidade de troca catiônica (CTC) e a saturação por bases (V\%) no solo. $\mathrm{Da}$ mesma forma, os micronutrientes $\mathrm{B}, \mathrm{Fe}, \mathrm{Mn}$, $\mathrm{Cu}$ e $\mathrm{Zn}$ apresentaram-se com maiores teores no solo.

- Em relação à produção, houve um significativo aumento linear na produção de grãos até a dosagem de $60 \mathrm{Mg} \mathrm{ha}^{-1}$, sendo que, para a dosagem superior, houve efeito inibidor em função do excesso de alguns nutrientes ou elementos supressores do crescimento vegetal, contidos no biossólido de suinocultura.

- Recomenda-se para fins de descarte agrícola do biossólido de suínos, até a dosagem de $60 \mathrm{Mg}$ ha $^{-1}$ para a cultura do feijoeiro.

\section{REFERÊNCIAS BIBLIOGRÁFICAS}

EMBRAPA - Empresa Brasileira de Pesquisa Agropecuária. Centro Nacional de Pesquisa de Solos. Sistema Brasileiro de Classificação de Solos. Brasília: EMBRAPA, 1999. 412p.
FAGERIA, N. K.; BARBOSA FILHO, M. P; STONE, L. F. Nutrição de fósforo na produção de feijoeiro. In: YAMADA, T; ABDALLA, S. R. S. (Org.) Fósforo na agricultura brasileira. Piracicaba-SP: POTAFOS, 2004, p. 435-455.

FUSCALDI, K. C.; PRADO, G. R. Análise econômica da cultura do feijão. Revista da Política Agrícola. Brasília, № 1, p. 24-24, jan/fev/mar, 2005.

KIEHL, E. J. Manual de edafologia: relações solo-planta. São Paulo: Editora Agronômica CERES, 1979, p. 76-110.

KUNZ, A. Tratamento de dejetos: desafios da suinocultura tecnificada. Suinocultura Industrial. Embrapa Suínos e Aves, 17 mar. 2005. Introdução. Disponível em: <http://www.ambientebrasil.com.br/compose r.php3?base=./agropecuario/index.html\&cont eudo=./agropecuario/dejetos_suinos.html> Acesso em 20.mar.2006.

LEMOS, R. C.; SANTOS, R. D. Manual de descrição de coleta de solos no campo. 2.ed. Campinas: Sociedade Brasileira dos Solos: Embrapa - SNLCS, 1984. 46p.

MALAVOLTA, E.; VITTI, G. C.; OLIVEIRA, S. A. Avaliação do estudo nutricional das plantas: princípios e aplicações. Piracicaba: POTAFOS, 1989. 201p. 
MALAVOLTA, E. Potássio, magnésio e enxofre nos solos e culturas brasileiras. Piracicaba: POTAFOS, 1982, 91p. (Boletim técnico, 4).

PERDOMO, C. C.; LIMA, G. J. M. M.; SCOLARI, T. M. G. Dejetos de Suinocultura. Ambiente Brasil, Embrapa Suínos e Aves, 2001. Introdução. Disponível em: $<$ http://www.ambientebrasil.com.br> Acesso em 20.mar.2006.

RAIJ, B. van; QUAGGIO, J. A. Métodos de análise de solo para fins de fertilidade. Campinas: Instituto Agronômico, 1983, 40p.

RAIJ. B. van; SILVA, N. M.; BATAGLIA, O. C.; QUAGGIO, J. A.; HIROCE, R.; CATARELLA, H.; BELLINAZZI JÚNIOR, R.; DECHEN, A. R.; TRANI, P. F. Recomendação de adubação e calagem para o Estado de São Paulo. Campinas: Instituto Agronômico, 1996, 285p. (Boletim técnico, 100).

SEGANFREDO, M. A. Informe Embrapa Equação dos dejetos. Suinocultura Industrial, Embrapa Suínos e Aves, 2000. A adubação com dejetos de suínos e a qualidade ambiental. Disponível em: <http://www.suinoculturaindustrial.com.br/site/ dinamica.asp?tipo_tabela $=$ cet\&id $=2384 \&$ cat egoria=manejo $>$ Acesso em 20.mar.2006.
SILVA, F. C.; BOARETTO, A. E.; BERTON, R. S.; ZOTELLIH, B.; PEXE, C. A.; BERNARDES, E. M. Efeito do lodo de esgoto na fertilidade de um Argissolo Vermelho-Amarelo cultivado com cana-deaçúcar. Pesquisa Agropecuária Brasileira. Brasília, v.36, n.5, p 831-840, maio 2001.

TOBIAS, A. C. T. Tratamento de resíduos de suinocultura: uso de reatores anaeróbios seqüenciais seguidos de leitos cultivados. 2002, 146f. Tese (Doutorado) - Faculdade de Engenharia Agrícola, UNICAMP, Campinas, 2002.

TOBIAS, A. T. C.; TEIXEIRA, N. T.; SHIGIHARA, R. Biossólido de origem suína na produção de alface (Lactuca sativa $L$.) cv. salad bowl green. Ecossistema. Espírito Santo do Pinhal - SP, v.26, n.1, p 40-41, jan/jul 2001.

TSUTIYA, M. T. Características de biossólidos gerados em estações de tratamento de esgotos. In: TSUTIYA, M. T.; COMPARINI, J. B.; ALEM, P. S.; HESPANHOL, I.; CARVALHO, P. C. T.; MELFI, A. J. MELO, W. J.; MARQUES, M. O. Biossólidos na agricultura. 1 ed., São Paulo: SABESP, 2001, p 89-131.

ZAR, J.R. Biostatistical analysis. 2.ed. Englewood Cliffs: Prentice-Hall, 1984. 718p. 